\title{
Motherhood and COVID-19: a Digital Psychoeducational Booklet for the Coping with the Pandemic Stressors
}

\section{Cassia Patricia Barroso Perry ${ }^{1}$ (D) - Ana Cristina Barros da Cunha ${ }^{1}$ (D) Karolina Alves de Albuquerque ${ }^{2}$ (D) - Andressa Leal Martins ${ }^{1}$ (D) Dayane Brandão Lima ${ }^{1}$ (D) Paula Caroline de Moura Burgarelli ${ }^{1}$ (D) . Vanessa Correia Fernandez Gonçalves ${ }^{1}$ (i)}

Accepted: 8 February 2021/ Published online: 13 April 2021

(C) Associação Brasileira de Psicologia 2021

\begin{abstract}
During the pandemic of COVID-19, the Brazilian Health Ministry declared that 2-week postnatal women are a high-risk population that demands special assistance. Considering that women at the postnatal period are more susceptible to anxiety and stress symptoms, our objective is to present a digital psychoeducational booklet analyzing its validity to help this target population to cope with the stress from the new coronavirus crisis. Based on the dispositional coping theory and positive psychology, this proposal was developed as a digital booklet to promote the maternal mental health and well-being based on informational and psychoeducational approaches. Information about the COVID-19, as well as coping strategies and positive practices, were presented to provide support for the coping with pandemic stressors. To validate the booklet, 12 women answered a Google Form via WhatsApp that included a free and informed consent form, a general data protocol, and a questionnaire with validity criteria (clarity of written, practical pertinence, theoretical relevance, and presentation). Content validity coefficients (CVC) were calculated for all criteria. The participants were on average 30 years old (A.V.=23-43), and half of them had a high school degree; $50 \%$ of them self-declared white and $25 \%$ black, and 2 of them declared themselves brown and 1 yellow. All CVC were $\geq 0.96$. These findings confirmed that our booklet can be considered a viable, useful, and efficient tool to help puerperium women during the pandemic, providing support for a resilient coping face to this new and critical moment.
\end{abstract}

Keywords Postpartum period · Stress · Coping · COVID-19 · Booklet · Health education

Cassia Patricia Barroso Perry

cassiaperry57@gmail.com

1 Instituto de Psicologia, Universidade Federal do Rio de Janeiro, Palácio Universitário da UFRJ Av. Pasteur, 205, Rio de Janeiro, RJ 22290-240, Brasil

2 Departamento de Terapia Ocupacional, Universidade Federal do Espírito Santo, Vitória, ES, Brasil 
The social and health crisis resulting from the pandemic of severe acute respiratory syndrome coronavirus 2 (SARS-CoV-2) has affected countries and people all over the world. The new coronavirus and its disease, COVID-19, have serious impacts for the physical (Chen et al., 2020) and emotional (Huang \& Zhao, 2020; Wang et al., 2020) health of the general population. This pandemic has been considered to be one of the biggest public health problems in recent decades, with severe psychological impacts on mental health (World Health Organization (WHO), 2020). Mental disorders related to COVID-19, such as depression, anxiety, and stress, have been identified among the population (Wang et al., 2020a). Measures to help people to deal with this psychological vulnerability are an emergency in Brazil (Schmidt et al., 2020). According to Zandifar and Badrfam (2020), the fast spread of COVID-19 and the uncertainties about its control and duration, as well as the severity of its outcomes, represent risks for people's mental health, with important impacts for more vulnerable groups, like the puerperal population (Brazil, 2020a).

According to the World Health Organization (2009), the postnatal period begins immediately after the delivery as a moment with major physical, hormonal, psychological, and social changes, which increases the woman's vulnerability for perinatal mental disorders, such as stress (Rodrigues \& Schiavo, 2011; Clout \& Brown, 2015), anxiety (Redzuan et al., 2020), and depression (Poles et al., 2018). Although a typical stress is expected during the puerperium to support women to be able to attend the newborn demands, more severe stressors may impact the perinatal mental health, with negative outcomes for the baby care (Fernandes et al., 2020). In addition, long-term stressful situations and higher levels of stress tend to worsen perinatal mental disorders and their outcomes (Gaillard et al., 2014). Maternal baby blues, postpartum depression, and puerperal psychosis can all be related to stressful maternal experiences during the pregnancy-puerperal cycle (Aas et al., 2020; Gaillard et al., 2014; Qobadi et al., 2016), with important impact for the baby's development and the mother-baby relationship (Hoffman et al., 2017).

Spinola et al. (2020) affirm that mothers of children under 1 year old can show higher rates of depression and stress symptoms than the general population during the pandemic. The COVID-19 pandemic stressors can have impact on postnatal women, especially because the mothers fear related to the baby getting infected by the coronavirus (Spinola et al., 2020). Thus, the puerperium population suffers the impact of specific pandemic stressors on their mental health. Therefore, it is important to focus on the psychosocial impact of COVID-19, in addition to physical outcomes.

The physical distancing and social isolation related to the COVID-19 pandemic, for example, can increase stress levels in the puerperium, with an important impact on the perinatal mental health. Stressors, such as lack of social support, are a predictor of perinatal mental disorders, such as postpartum depression (Corrigan et al., 2015), with negative outcomes for the mother-baby binomial (Slomian et al., 2019). The pandemic stressors can be interpreted by the mother as challenges, threats, or damages to the needs of the self (Carver \& Scheier, 1994; Carver \& Connor-Smith, 2010), when she should adopt “(...) cognitive and behavioral efforts to manage specific external and internal demands that are appraised as exceeding the personal resources to cope with the stress" (Lazarus \& Folkman, 1984, p. 141).

The Brazilian Health Ministry Program for Humanization of Prenatal and Childbirth Care (Brazil, 2000) attested that health education measures for pregnant and postpartum 
women should focus on preventing risks for the perinatal mental health. Considering this, this study was based on the coping dispositional theory (Carver \& Connor-Smith, 2010) and positive psychology (Seligman \& Csikszentmihalyi, 2000) assumptions. Based on the cognitive coping theory (Lazarus \& Folkman, 1984), the coping dispositional theory proposed by Carver and collaborators (Carver \& Scheier, 1994; Carver \& Connor-Smith, 2010) assumes that people usually adopt engaged or disengaged strategies based on their cognitive interpretation of stressors and their coping styles, which are the person's tendencies to deal with stressful situations. For example, a puerperal woman who tends to adopt an engaged coping style may interpret the pandemic stressors as challenges, and she copes with this using engaged strategies, such as seeking for social support for instrumental reasons, to better understand the COVID-19 and its consequences. On the other hand, denial is a disengaged coping strategy that can be used by puerperal women to avoid an active and effective confrontation with the pandemic stressors (Carver \& Connor-Smith, 2010). Although those coping tendencies suggest a particular style for dealing with stress, people do not always adopt the same strategies to deal with problem situations. The person can cope with the problem by using sometimes engaged strategies, such as seeking for social support for instrumental reasons, seeking for social support for emotional reasons, positive reinterpretation, growth, planning, acceptance, and active coping, or by using disengaged strategies, such as denial or mental disengagement and/or behavioral disengagement, in another times. The coping style will depend on the interpretation of the stress situation, as well as the personal and contextual resources available to deal with the self-tension (Carver \& Connor-Smith, 2010). According to the coping dispositional theory, the engaged coping strategies can be learned as psychological resources to be adopted in stressful situations, contributing to a more resilient coping.

Based on the positive psychology approach, mental health is an inherent and potential human capacity that can be developed by positive psychological interventions (Rashid \& Seligman, 2018). Different from an absence of mental disorders, human mental health includes personal abilities to develop resilient strategies for psychological, emotional, and social well-being that can be mediated and/or moderated by positive personality traits, such as the creativity and hope (Peterson \& Seligman, 2004; Seligman \& Csikszentmihalyi, 2000). Compassion and optimism, for example, are positive personality traits that are associated with an engaged coping style (Carver et al., 2010; Singer \& Klimecki, 2014) that can promote efficient responses to adversity and distress (Carver \& Connor-Smith, 2010). Optimism with self-regulation, for example, is a stress moderator related to physical and mental health (Carver \& Connor-Smith, 2010; Carver \& Scheier, 1994; Carver et al., 1989).

Therefore, positive psychology offers a positive approach of mental health and stress coping, both related to personal capacities to develop positive styles to deal with emotions and address stress. Positive psychology interventions are based on the development of personal strengths of human character and virtues, which can be cultivated to increase the human potential for mental health and personal resources to deal with problem situations (Peterson \& Seligman, 2004). The promotion of compassion, creativity, optimism, and empathy are examples of positive psychological interventions, which can be practiced intentionally according to personal resources and needs to reduce the negative impacts on the mental health and increase the levels of subjective well-being or happiness during the pandemic (Rashid \& Seligman, 2018; 
Zanon et al., 2020). Finally, a systemic and bioecological perspective was adopted to interpret the pandemic stressors in a contextual way (Bronfenbrenner, 1979, 2005). This perspective was used to develop and structure the booklet, identifying the specific pandemic stressors according to different contexts where women and her family suffer the impact on her well-being and mental health.

Furthermore, according to the Royal College of Psychiatrists (2011), health education interventions to promote healthy lifestyles are efficient measures to help with mental health. These interventions are more accessible and viable if they can be based on booklets and information materials (Schmidt et al., 2020), and according to a research conducted in Canada, mothers and fathers tend to prefer booklets as a form of getting information, considering them extremely helpful (Abbass-Dick \& Dennis, 2018). Based on the importance of positive psychological interventions and the developing of engaged coping styles to deal with the pandemic, the objective of this study is to present a digital psychoeducational booklet analyzing its validity to help postnatal women to cope with the stress from the new coronavirus crisis. For this, we present and explain the booklet developing process and analyze its validity to help mothers of babies under 6 months old to cope better with the stress of the new coronavirus crisis.

\section{Method}

This is a methodological study approved by the Research Ethics Committee (CAEE N. 31525720.0.0000.5275) conducted in two stages: (1) construction of the digital booklet Maternity in times of COVID-19: how to face the pandemic when I am the mother of a baby under six months? and (2) evaluation of the content validity of the booklet by judges from the target population.

During the COVID-19 pandemic, the Task Force XXX (text omitted for no identification of authors), composed by three psychologists, three occupational therapists, and eight graduate psychology students, develops digital informational and psychoeducational resources to help pregnant and puerperal women to cope with the pandemic stressors. According to this, the booklet Maternity in times of COVID-19: how to face the pandemic when I am the mother of a baby under six months? was developed based on an interdisciplinary approach.

\section{Booklet Development}

In general, the positive psychological interventions and coping strategies presented in the booklet were proposed to help mothers of babies under 6 months old to cope better with the stress of the COVID-19 pandemic. The booklet proposal was to promote positive affects, such as self-compassion, optimism, and hope, associated with engaged coping strategies, such as the positive reinterpretation, growth, and acceptance, to guarantee the subjective well-being and minimize the risks of psychological distress during the pandemic.

Based on this purpose, specific stressors for mothers of babies under 6 months old and typical stressors from the pregnancy-puerperal cycle, such as the mother adaptation to the new routine and baby care, were searched for on websites and in national and 
international literature about the COVID-19. Stressors presented in public policies about the COVID-19 for puerperal population were also identified (Brazil, 2020a, 2020b, 2020c, 2020d, 2020e; Fiocruz Brazilian Human Milk Bank Network, 2020; Royal College of Obstetricians and Gynecologists, 2020). Those stressors were presented in the booklet as direct questions to postpartum women, with suggestions of coping strategies and positive psychological intervention. General information about the protection and prevention of COVID-19, specific to the puerperal population, was also included.

All of the booklet content was developed based on the bioecological and systemic perspective (Bronfenbrenner, 1979, 2005) to present a theoretical and practical analysis of the pandemic scenario of COVID-19. According to this theory, the different contexts of the mother, her baby, and her family are related to a developmental dynamic involved in the promotion of maternal mental health. Dynamic proximal processes, like face-to-face interactions and mother-infant relationships, as well as distal processes, like cultural and social conditions, values, and beliefs of the puerperal woman and her family, have impact on the health and development (Bronfenbrenner, 2005). Otherwise, variables like government public policies, healthcare services, as well as personal lifestyles and beliefs about health and well-being represent influences for the family context (Linhares \& Enumo, 2020) and, consequently, on the postpartum dynamic cycle.

Thus, the theoretical approach of the booklet was based on positive psychology and dispositional coping theory, interpreted on a bioecological and systemic perspective. Based on this, the coping with pandemic stressors was understood focusing the intersubjective relations among the target population and its microsystem contexts and variables. On the other hand, all positive interventions were proposed to improve coping ways to face those stressors, considering the bioecological and systemic aspects from the context (the puerperium) and the person (puerperal women with baby under 6 months old) during the time (the pandemic moment).

Based on this, the specificities of the pandemic for the puerperal population were considered and organized in two thematic sections of the booklet: (a) about the puerperium and being a mother during the pandemic, with themes focused on the puerperal woman and her support and family network, and (b) first steps for the newborn baby care, with themes focused on how to attend the demands and needs of a baby during the pandemic. The main stressors and their effects on the perinatal mental health, as well as how puerperal women may interpret the stressors (such as challenge, threat, or harm to the self) and their related feelings, were presented in each booklet section.

In Table 1, the booklet sections and their sub-themes are presented, with stressors in the form of questions addressed to postpartum women, followed by the coping strategies and positive psychological interventions.

Considering that mindfulness is a great positive psychological intervention which contributes to well-being and quality of life (Birtwell et al., 2019; Grossman et al., 2004), a mindfulness-based meditation exercise was included at the end of the booklet. It highlights the advantage of mindfulness, as well as its feasibility to be included in the daily routine of the woman and her family. Other exercises, such as face-to-face play games with visual contact and motor stimulation between mother and baby, were 


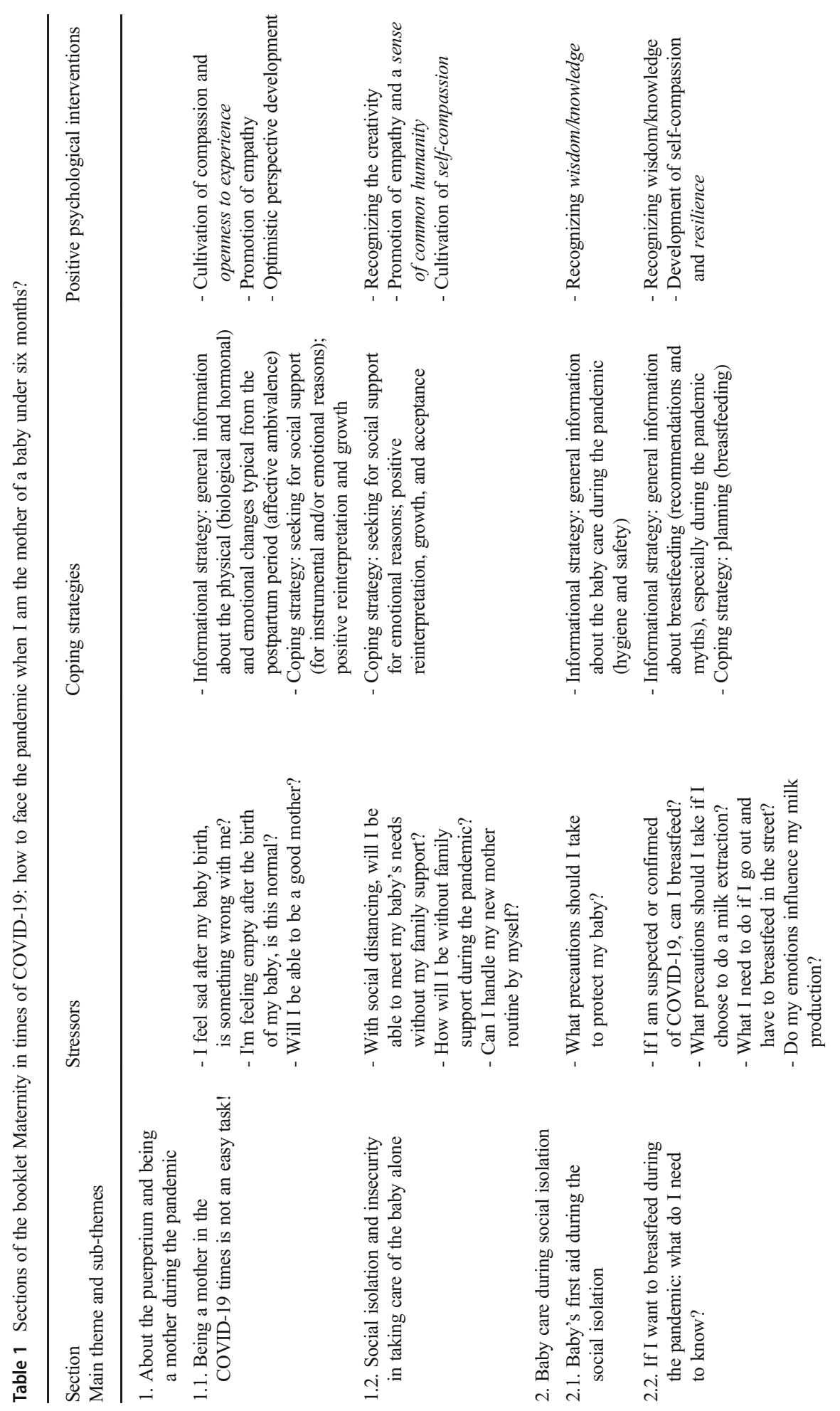




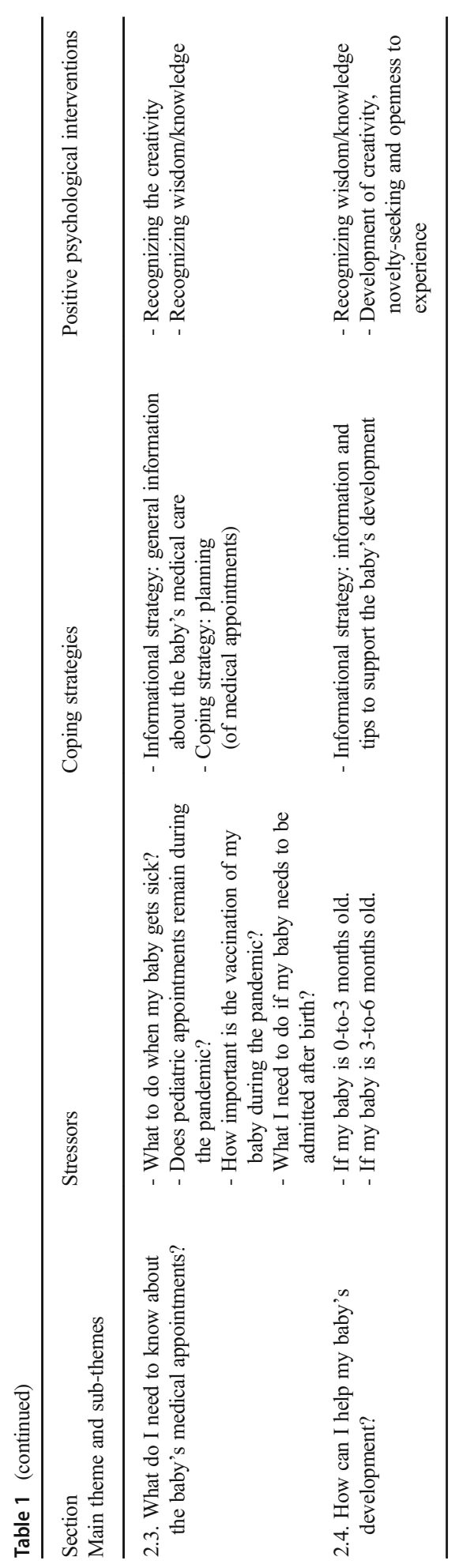


included in the booklet to encourage maternal practices to stimulate the infant development.

For digital graphic and artistic development, a free virtual platform, Canvas app, was used. The digital format was chosen to facilitate the booklet dissemination on social networks and via WhatsApp by health professionals. All of the booklet content was based on the translation of the knowledge and scientific evidence into a comprehensible and accessible written for the target population. The final version of the booklet has 46 pages, including cover, summary, and back cover.

\section{Evaluation of the Booklet by the Target Population: Content Validity by Postpartum Women}

\section{Target Population}

Twelve $(N=12)$ puerperal women were recruited to evaluate the booklet. The average age of them was 30 years old (A.V.=23-43), and half of them had a high school degree, three had higher education, and three had postgraduate degrees. The majority of them self-declared white (50\%), while three of them declared themselves black, 2 brown, and 1 yellow. Furthermore, $50 \%$ of them were married, while the other half was single, and 91.6\% were from the State of Rio de Janeiro, being one from Espírito Santo.

\section{Instruments for Data Collection}

For data collection, a form was developed on Google Forms with an informed consent form (ICF), approved by the Research Ethics Committee (CAEE N. 31525720.0.0000.5275); a general data protocol, to identify socio demographic data; and a questionnaire to assess the content validity of the booklet according to these criteria: (a) clarity of written, to evaluate the adequacy of the booklet writing for the postpartum women, and if the booklet written was accessible and well understood by this target population; (b) practical pertinence, to evaluate the importance of the booklet to help puerperal women, that is, if the booklet content was adequate to help the puerperal women to adopt the positive interventions on their day-to-day living in a practical way; (c) theoretical relevance, to evaluate whether the pandemic stressors and psychological strategies presented on the booklet were recognized by the puerperal women as relevant and helpful to cope with the pandemic; and (d) presentation, to evaluate the aesthetics and visual organization of the booklet, that is, if its layout, color, and format were aesthetically pleasing for puerperal women and encourage them to read the booklet. All criteria were evaluated quantitatively adopting a five-point Likert scale $(1=$ very little, $2=$ little, $3=$ medium, $4=$ very, and 5= very much). There was no set time for the completion of the questionnaire. Comments, concerns, and suggestions from postpartum women were analyzed qualitatively and included at the final version of the booklet.

\section{Data Collection Procedures}

Twelve puerperal women were randomized from a total of 30 women first recruited in a convenience method. They were invited to be a part of the validation study as target 
population judges. Two ways of recruitment were adopted: part of them were recruited by a psychologist of the team during their postpartum hospitalization in a public maternity hospital at Rio de Janeiro (Brazil), and the other part of the sample was contacted through the Instagram page of the research group. The inclusion criteria were as follows: mothers of children under 6 months, with no risks pregnancy and typical baby development (without disability), and belonging to any socioeconomic level and without discrimination of race/color. The exclusion criteria were the lack of internet access.

The participants were contacted via WhatsApp when the purpose of the research was presented, the study objectives were explained, and the evaluation procedures were clarified. First, they were required to read the booklet and evaluate it using a Google Forms accessed with a link sent via WhatsApp message. This had three sections: informed consent form, a general data protocol, and the questionnaire to evaluate the booklet content. The Google Forms platform was chosen because of its easy access and manipulation for both the evaluators and researchers. Furthermore, it also facilitated the processing data showing, for example, the percentage of the ethnicity, age, and schooling of target population judges.

\section{Data Analysis}

A descriptive statistical analysis was performed using the guidelines for content validity of psychological instruments studies proposed by Cassepp-Borges et al. (2010) and Hernández-Nieto (2002). Based on this, the content validity coefficients (CVC) were calculated for all content validity criteria, adopting a $\mathrm{CVC} \geq 0.80$ as a cutoff point (Hernández-Nieto, 2002).

\section{Results}

The results of the content validity coefficients (CVC) of the booklet are summarized in Table 2.

Only 7 (seven) judges inserted comments or suggestions that were analyzed qualitatively as shown in Table 3 .

Table 2 Content validity coefficients (CVC) of the booklet by postpartum women $(N=12)$

\begin{tabular}{|c|c|c|c|c|c|c|c|c|c|c|c|c|c|}
\hline \multicolumn{12}{|l|}{ Puerperal women } & \multirow[b]{2}{*}{$\mathrm{P} 12$} & \multirow[t]{2}{*}{$\mathrm{CVC}^{*}$} \\
\hline Rating criteria & P1 & $\mathrm{P} 2$ & P3 & $\mathrm{P} 4$ & P5 & P6 & P7 & P8 & P9 & $\mathrm{P} 10$ & $\mathrm{P} 11$ & & \\
\hline Clarity of written & 5 & 4 & 5 & 5 & 5 & 5 & 5 & 5 & 5 & 5 & 5 & 5 & 0.96 \\
\hline Practical pertinence & 5 & 5 & 5 & 5 & 5 & 5 & 5 & 5 & 5 & 5 & 5 & 5 & 1 \\
\hline Theoretical relevance & 5 & 5 & 5 & 5 & 5 & 5 & 5 & 5 & 5 & 5 & 5 & 5 & 1 \\
\hline Presentation & 5 & 5 & 5 & 5 & 5 & 5 & 5 & 5 & 5 & 5 & 5 & 5 & 1 \\
\hline
\end{tabular}

$* C V C$ content validity coefficient 
Table 3 Qualitative evaluation of the booklet by postpartum women according to the content validity criteria $(N=12)$

\begin{tabular}{|c|c|}
\hline Categories & Puerperal women's observations and suggestions \\
\hline Clarity of written & $\begin{array}{l}\text { "The booklet is a great material to help pregnant women and mothers because it brings } \\
\text { clear and accessible information that can clarify doubts that arise in the postpartum } \\
\text { period, especially in this difficult context of the pandemic!" }\end{array}$ \\
\hline $\begin{array}{l}\text { Theoretical } \\
\text { relevance }\end{array}$ & $\begin{array}{l}\text { "Puerperium already isn't the best time, especially in times of pandemic... Thanks for this } \\
\text { material and for caring for us!" } \\
\text { "It is of the utmost importance that we learn more about this subject! And to make me sure } \\
\text { that we can take even more precautions!!!" }\end{array}$ \\
\hline Presentation & $\begin{array}{l}\text { "Very well prepared and highly explanatory material" } \\
\text { "It's wonderful, very complete, I loved it!" }\end{array}$ \\
\hline Content & $\begin{array}{l}\text { "I think that a plan or tips from a pediatrician can be a great help for future mothers. As an } \\
\text { example, hygiene material needed for baby care, type of food if the mother does not } \\
\text { want to breastfeed, etc." } \\
\text { "It would be nice to put real experiences" }\end{array}$ \\
\hline
\end{tabular}

\section{Discussion}

The COVID-19 pandemic represents a global crisis with severe vulnerability for physical, mental, and emotional health (Fiorillo \& Gorwood, 2020) and important impacts for vulnerable groups, such as pregnant and postpartum women. Social distancing, the only effective measure to combat coronavirus, can pose a threat to mental health because it increases levels of stress, anxiety, and depression (Wang et al., 2020a). According to this, the booklet "Maternity in times of COVID-19: how to face the pandemic when I am the mother of a baby under six months?" can minimize the impacts of the pandemic by presenting scientific information and knowledge in accessible writing to promote the mental health and subjective well-being of the postpartum population. In addition, the booklet is able to achieve women of all socioeconomic levels, regardless of education level because it presents the main pandemic stressors focused directly on the doubts of the mothers of the pandemic in an interactive way.

All content validity criteria were positively evaluated by the puerperium women, highlighting theoretical relevance, practical pertinence, and presentation of the booklet that achieved maximum CVCs (CVC 1.0). Also, the clarity of the booklet written was well evaluated with CVC 0.96. These findings confirm that the booklet can be considered a valid and appropriate resource that is relevant and pertinent to the target population with an aesthetically pleasing presentation. Also, the CVCs above the cutoff point $(\geq 0.80)$ attested that the booklet can be considered an accessible tool due to its written. So, the booklet written was considered easy to understand by the target population. In this way, the booklet achieved its main purpose, which was to contribute to promoting maternal mental health and puerperal women well-being by offering strategies to minimize the negative stress outcomes resulting from the pandemic.

Considering that the psychological distress can be reduced when the population is satisfied with the health information measures (Ho et al., 2020), the maximum CVC of theoretical relevance $(\mathrm{CVC}=1)$ and practical pertinence $(\mathrm{CVC}=1)$ criteria of the 
booklet were extremely important. These findings highlight the booklet content as an adequate resource for puerperal women who suffer during the pandemic. The booklet provided practical interventions to manage the stressors on their routine and improve their coping styles. Furthermore, these results also show that not only the pandemic stressors could be recognized by the target population, but also the psychological theories presented in the booklet were considered important by them, providing emotional support during the pandemic.

The high CVC of the booklet presentation should also be highlighted. A good presentation is important to maintain the public's attention and interest (Fonseca et al., 2004). Moreover, the figures presented in the booklet supported the interpretation of information and made it easier to understand (Wong, 2011). This is especially important during the pandemic, when the measures based on visual tips have been shown to be more efficient to reduce distress (Ho et al., 2020). Thus, drawings of puerperal women in different situations were used along the booklet to facilitate that the target population would identify with the material. In addition, a summary was also inserted in the booklet in order to facilitate the access of content according to each situation. Thus, the $\mathrm{CVC}=1$ of the booklet presentation confirms its attractive form for the target population. Finally, the criteria clarity of written also showed high CVC $(=0.96)$. According to Echer (2005), the educational material can be understood as an instrument that strengthens the treatment guidelines for patients and family members that is particularly important when it presents a clear language and accessibility for all layers of society, regardless of their level of instruction.

The participation of postpartum women in the booklet content evaluation was significant because it allowed to assure the inclusion of the women's perspective and their concerns and demands during the pandemic. Thus, based on the qualitative evaluation from puerperal women, the booklet was considered an efficient resource to attend to their necessities and clarify their doubts about the COVID-19 control measures. On the booklet, they found informational content and psychological support to deal with their insecurities, fears, and distresses, as illustrated on this woman's report: "Puerperium already isn't the best time, especially in times of pandemic, thanks for the material provided and for caring for us!". For sure, the puerperium is a complex and difficult time for women, who feel more insecure (WHO, 2009). To live this moment during a pandemic can be even more distressful. The lack of family and social support due to the coronavirus control measures may result in greater insecurity for the mother, especially for the newborn care. Because of this, the typical stress of the puerperium can increase. Brazilian literature affirms that this stress can increase the chances of negative outcomes for child development during the COVID-19 pandemic (Linhares \& Enumo, 2020).

To help mothers deal with the pandemic stressors, self-compassion was presented in the booklet as a positive psychological strategy to encourage them to be more empathetic with themselves, to understand and accept their own limitations as typical pandemic difficulties. In addition, self-care and resilience were also the focus of the booklet to encourage mothers to, along with their family support, plan a healthier environment for the baby's development, especially because the baby's main caregivers have great responsibility on the infant development and their emotional and behavioral self-regulation (Bronfenbrenner, 2005). Moreover, promoting maternal mental health assures positive affective exchanges with the baby, which positively influences the child's development. Maternal mental health disorders negatively affect 
caregiver-infant attachment and bonding, with potential long-term negative effects on the caregiver-infant dyad. Considering that, babies need to be involved in an affective relationship with their caregivers. This supports their socioemotional development and represents an important base for the infant's healthy development (Hoffman et al., 2017). So, informational support resources, like the booklet "Maternity in times of COVID-19: how to face the pandemic when I am the mother of a baby under six months?", can help mothers to guarantee a good and healthy context of attachment relationship between her and her child. This provides support to minimize negative consequences or disturbances on the baby behavior and development. Its evaluation, both quantitative and qualitative, suggests that it achieved its objective, confirmed by comments such as "very well prepared and highly explanatory material," which "brings clear and accessible information that can clarify doubts that arise in the postpartum period."

The booklet offered knowledge about the typical psychological changes from the puerperium, as well as information on public policies related to the pandemic. In section 1, about the puerperium and being a mother during the pandemic, for example, the affective ambivalence and the specific feelings from the puerperal-pregnancy cycle, which are not always known to many puerperal women, were presented to mothers in an accessible written: "This all seems like a real roller coaster of contradictory feelings, which seems to have no end! It is a mixture of joys, sorrows, fears, and even feelings of confidence but, in the end, everything will be fine!". This allowed the women to recognize themselves as capable of understanding these psychodynamic changes, helping them to accept and embrace their feelings through self-compassion.

Coping strategies and positive psychological interventions presented in that section focused on stressors such as helplessness resulting from the lack of family support, the social isolation, and insecurities concerning baby caring. Also, the most emphasized coping strategy was the seeking for social support (for instrumental and/or emotional reasons) to encourage them to share the domestic tasks and baby care with family members in order to help them to deal with helplessness. Maternal helplessness has an impact on the maternal mental health, with outcomes such as puerperal depression (Corrigan et al., 2015), which affects the mother-baby relationship, as much as the child's development (Slomian et al., 2019). Furthermore, there is evidence that the social support is a protective factor for people's health (Holt-Lunstad et al., 2015), with particular importance for the woman's health and baby-mother dyad.

The concerns about baby care during the pandemic were also presented in the booklet. Section 2, baby care during the social isolation, presented informational strategies, emphasizing the importance of hygiene and the pandemic control rules, like the use of masks only in children older than 2 years old (Royal College of Obstetricians and Gynecologists, 2020). In addition, the coronavirus transmission (Center of Disease Control and Prevention, 2020b) was also presented in the booklet to help mothers better understand the protection measures. Based on this, puerperal women were encouraged to adopt these measures, understanding them as sufficient for the baby care, as well as helping them to cope with the feelings of fear of the COVID-19.

The positive psychological interventions and coping strategies of the booklets in section 2 were directed related to the maternal concerns about the newborn caring without family support, as well as the difficulties in breastfeeding and the maternal expectations about mother-baby relationship. The coping strategy planning was the 
main focus of this section to help mothers to organize and be involved in the new routine, as well as handle breastfeeding difficulties. Planning is a coping strategy focused on problem-solving in an active way, when the person thinks about and chooses the best way to cope with the stressor (Carver et al., 1989). According to Carver et al. (1989), planning is associated with positive reinterpretation and growth besides seeking for social support. Moreover, it is inversely associated with denial and disengaged strategies and positively associated with optimism and self-esteem, being an important strategy to cope with stress (Carver et al., 1989).

Furthermore, to increase the woman's confidence to overcome the challenges of baby care during the pandemic, positive psychological interventions, like the promotion of self-compassion, optimism, and self-care, were suggested in the booklet. Learning skills to cultivate these positive emotions can be a tremendously beneficial way of achieving well-being (Rashid \& Seligman, 2018). Besides that, the investment in positive feelings, cognitions, and behaviors improves the development of human potential (Seligman, 2011). Studies confirm that the self-care is related to the decrease of anxiety and depression symptoms, as well as the greater life satisfaction (Neff, 2009). Self-confidence also has a positive impact on mental health (Atherton et al., 2016). It is important to emphasize that the booklet focused on easy and viable daily activities that do not require financial expenses; so, it can help mothers from different socioeconomic levels to overcome the difficulties imposed by the pandemic.

In both booklet sections, a subsection "How about some exercises?" was proposed. For section 1, an exercise of self-reflection was proposed to promote an optimistic perspective about the women's experience of motherhood. This can refocus a subjective woman's perspective in order for them to realize their maternal competence. Feeling competent as a mother is important to assure a better experience of motherhood and to provide proper baby care (Leahy-Warren, 2005). In section 2 of the booklet, an exercise to strengthen the mother-baby affective bond was proposed to stimulate the interpersonal connection between mother and child. Considering that the bond between mother and baby allows the caregiver to attend to the infant's needs, the booklet helped mothers to avoid feelings of anguish in their baby, especially because it is important that parents and children be sufficiently emotionally available to each other (Bornstein \& Manian, 2013).

Furthermore, an example of a mindfulness-based meditation exercise was also included in the booklet to offer mothers a resource to manage anxiety and minimize the typical distress from the pandemic (Ramírez-Ortiz et al., 2020). Literature indicates that mindfulness can improve the coping with anxiety and stress (Grossman et al., 2004). Mindfulness reduces psychological suffering, cultivates positive qualities, assists in changing the perspective of the stressing event, and promotes well-being (Birtwell et al., 2019; Grossman et al., 2004). Therefore, the mindfulness exercise presented in the booklet aimed to promote the mother's self-regulation of thoughts, emotions, and behaviors to be able to recognize her resources and search for alternative strategies to address the challenges of the pandemic.

Considering that professional assistance is particularly important to help and encourage breastfeeding (Burns \& Schmied, 2017), information about this was also offered in booklet section 2.2. "If I want to breastfeed during the pandemic: what do I need to know?". The booklet encouraged breastfeeding by explaining its benefits and clarifying the recommendations of Brazilian Society of Pediatrics (2020a) and the 
Center of Disease Control and Prevention (2020a). Furthermore, mothers were also informed about breastfeeding in case of suspected or confirmed COVID-19, based on the Royal College of Obstetricians and Gynecologists (2020) recommendations. Breastfeeding brings different benefits for both mother and baby, such as lower rates of breast cancer (Ciampo \& Ciampo, 2018), the increasing of oxytocin production, and the mother-baby bonding (Feltner et al., 2018). The booklet explained about the specific aspects involved in breastfeeding and contributed to strengthen the mother's confidence (Feltner et al., 2018) and autonomy to breastfeed (Burns \& Schmied, 2017). Also, in this booklet section, the mothers' satisfaction could be improved by encouraging them to overcome the difficulties (Wouk et al., 2019).

Finally, changes during the pandemic in pediatric follow-up and the vaccination schedule of newborns by the Brazilian Immunization Society (2020) and the Brazilian Society of Pediatrics (2020b) were also presented in the booklet. To address these changes, mothers were encouraged to seek medical guidance for their doubts and call their pediatrician, if necessary. Studies indicate that informational support results on greater confidence and ensures a better motherhood experience (Leahy-Warren, 2005). According to this, information and guidance on the postnatal period during the pandemic for mothers and her newborn were offered in the booklet based on the national (Brazilian Immunization Society, 2020; Brazilian Society of Pediatrics, 2020b; Fiocruz Brazilian Human Milk Bank Network, 2020) and international public policies (Center of Disease Control and Prevention, 2020b; Royal College of Obstetricians and Gynecologists, 2020).

In this way, the booklet has a proposal to facilitate the access to information about COVID-19 by mothers in order to help them be confident to deal with the pandemic stressors. Surely, the COVID-19 pandemic is a completely different human experience that results in significant impact on puerperium and maternal tasks. It will require the mother to adapt to the different demands from the typical routine of puerperium and adopt resources to cope with this global crisis. Coping strategies and positive psychological interventions proposed in the booklet are resources that can help mothers develop new strategies to assure their well-being and ensure their mental health during the pandemic.

Measures, such as social isolation, result in higher levels of stress and anguish. Although social networks help in social contact, the restriction of interpersonal relationships is potentially stressful, with significant impacts for the construction of motherhood (Corrigan et al., 2015; Slomian et al., 2019) because a woman cannot have her family support during the postpartum period. The confinement and the distancing of socio-affective and intergenerational relationships have impacts on mother learning about neonatal care. Also, this affects the well-being, the sense of competence, and the self-efficacy of these "pandemic mothers", with outcomes to important maternal tasks, such as breastfeeding (Corrigan et al., 2015; Slomian et al., 2019). By focusing on subjective well-being and hope for better days, as positive psychological strategies, psychoeducational resources to deal with the new routine imposed by the pandemic were provided. For example, the booklet suggested the participation of babies in video calls with family members as an opportunity for the family to follow the child's development and growth during the social isolation imposed by the pandemic. 
It is important to highlight that insufficient information may result in mental disorders (Fiorillo \& Gorwood, 2020). Considering that depression symptoms tend to worsen in the face of excessive news from the pandemic, it is important to provide reliable information about the COVID-19 in order to promote security and engaged and resilient coping strategies for mothers. Moreover, positive psychological interventions help mothers to manage stress and other disorders resulting from social isolation. Therefore, the booklet is a complementary and accessible educational resource for the puerperal population, as illustrated by these comments: "It is of the utmost importance that we learn more about this subject! And make sure that we can take even more precautions!!!". This is an example of the coping strategy "Seeking for social support for instrumental reasons," which represents an active seeking for advice, help, or information to cope with stress (Carver et al., 1989).

Although physical health has been the focus of government measures for the COVID-19 pandemic, mental health problems should not be neglected (Fiorillo \& Gorwood, 2020), especially mothers' concern about the baby's physical health, illustrated on this woman comment: "[...] tips from a pediatrician can be of great help to future mothers. As an example, hygiene material needed for baby care [...]". Considering that the COVID-19 is a totally unknown disease, maternal distress related to the physical risks for her and her baby are expected. Moreover, face to the increasing of the pandemic negative outcomes for the population mental health (Fiorillo \& Gorwood, 2020; Wang et al., 2020a), psychoeducational resources like the booklet "Maternity in times of COVID-19: how to face the pandemic when I am the mother of a baby under six months?" are necessary.

The high content validity coefficients (CVC) of the booklet supports that it is valid to promote mental health, well-being, and a resilient coping with the stress from the pandemic. However, it is important to consider its limitations. First, due to COVID-19s impermissibility, new information about this disease is on time. This requires a constant updating of the information in the booklet that the team has been doing. Second, even though the high content validity coefficients, the judges were puerperium women in a busy routine addressed to their newborn demands that could impact on the evaluation of a 46-page booklet in a short period of time. The refusal of some postpartum women invited to analyze the booklet can support this; however, all participants had their own time to send their evaluation. Despite their full-time routine devoted to her babies and household chores, we can assume that they had enough time to analyze and evaluate the booklet. Moreover, considering that we used a convenience sample, it may not represent a real target population. Thus, we suggest future studies with a more diverse sample, especially with mothers with elementary education who could have difficulty to understand the material. Finally, the booklet was not evaluated by experts, who could contribute to the accuracy of the content addressed. However, it is important to emphasize that it was developed by a multiprofessional team, with psychologists and occupational therapists specialized in Perinatal Psychology and Maternal Child Health.

Despite these limitations, it is important to highlight that, although many materials were developed during the pandemic, few of them underwent a more systematic evaluation, as proposed in this study. Besides that, it is important to highlight the potential of the booklet to offer informational and emotional support for mothers with 6-month-old babies. Considering that it is a digital and accessible resource, the booklet can be used at any time, including post-pandemic times, because it also includes general information about 
the puerperium, like the mindfulness intervention and breastfeeding orientation. Finally, digital booklets can be important measures to inform and guide the population with reliable content based on scientific evidence about the COVID-19 for prevention and mental health promotion. The psychological impacts of this pandemic for the general population, and particularly for the new mothers, are unquestionable, especially because the pregnancy-puerperal cycle is a period of intense changes in the woman's life, with physical and psychological outcomes. Therefore, the booklet "Maternity in times of COVID-19: how to face the pandemic when I am the mother of a baby under six months?" can be considered an important resource for preventing negative outcomes for women's mental health in the postpartum period and ensuring a motherhood and familiar positive experiences, even during this COVID-19 pandemic.

Acknowledgements We are grateful for the Laboratório de Estudos, Pesquisa e Intervenção em Desenvolvimento e Saúde (Laboratory of Study, Research and Intervention in Development and Health), Maternity School Hospital of Universidade Federal do Rio de Janeiro.

Author Contribution Conceptualization: Cassia Patricia Barroso Perry, Ana Cristina Barros da Cunha, Karolina Alves de Albuquerque, Andressa Leal Martins, Dayane Brandão Lima, Paula Caroline de Moura Burgarelli, and Vanessa Correia Fernandez Gonçalves. Methodology: Cassia Patricia Barroso Perry, Ana Cristina Barros da Cunha, Karolina Alves de Albuquerque, Andressa Leal Martins, Dayane Brandão Lima, Paula Caroline de Moura Burgarelli, and Vanessa Correia Fernandez Gonçalves. Formal analysis and investigation: Cassia Patricia Barroso Perry, Andressa Leal Martins, Dayane Brandão Lima, Paula Caroline de Moura Burgarelli, and Vanessa Correia Fernandez Gonçalves. Writing-original draft and preparation: Cassia Patricia Barroso Perry, Andressa Leal Martins, Dayane Brandão Lima, Paula Caroline de Moura Burgarelli, and Vanessa Correia Fernandez Gonçalves. Writing-review and editing: Ana Cristina Barros da Cunha and Karolina Alves de Albuquerque. All authors contributed to and have approved the final manuscript.

Data Availability The datasets generated during and/or analyzed during the current study are available from the corresponding author on reasonable request.

Code Availability Not applicable.

\section{Declarations}

Ethics Approval Approval was obtained from the Ethics Committee of the Maternity School Hospital of Universidade Federal do Rio de Janeiro (ME-UFRJ). The procedures used in this study adhere to the tenets of the Declaration of Helsinki.

Consent to Participate Informed consent was obtained from all individual participants included in the study.

Consent to Publication The participant has consented to the submission of the case report to the journal.

Competing Interests The authors declare no competing interests.

\section{References}

Aas, M., Vecchio, C., Pauls, A., Mehta, M., Williams, S., Hazelgrove, K., Biaggi, A., Pawlby, S., Conroy, S., Seneviratne, G., Mondelli, V., Pariante, C. M., \& Dazzan, P. (2020). Biological stress response in women 
at risk of postpartum psychosis: The role of life events and inflammation. Psychoneuroendocrinology, 113, Article 104558. https://doi.org/10.1016/j.psyneuen.2019.104558.

Abbass-Dick, J., \& Dennis, C.-L. (2018). Maternal and paternal experiences and satisfaction with a coparenting breastfeeding support intervention in Canada. Midwifery, 56, 135-141. https://doi.org/10.1016/ j.midw.2017.10.005.

Atherton, S., Antley, A., Evans, N., Cernis, E., Lister, R., Dunn, G., Slater, M., \& Freeman, D. (2016). Selfconfidence and paranoia: An experimental study using an immersive virtual reality social situation. Behavioural and Cognitive Psychotherapy, 44(1), 56-64. https://doi.org/10.1017/S1352465814000496.

Birtwell, K., Williams, K., van Marwijk, H., Armitage, C. J., \& Sheffield, D. (2019). An exploration of formal and informal mindfulness practice and associations with wellbeing. Mindfulness, 10(1), 89-99. https://doi. org/10.1007/s12671-018-0951-y.

Bornstein, M. H., \& Manian, N. (2013). Maternal responsiveness and sensitivity reconsidered: Some is more. Development and psychopathology, 25(4 Pt 1), 957-971. https://doi.org/10.1017/S0954579413000308.

Brazil. (2000). Brazilian Health Ministry. Programa de Humanização no Pré-natal e Nascimento. (Technical Note Publication No. 569). Federal Government of Brazil. Recovered from http://bvsms.saude.gov.br/ bvs/saudelegis/gm/2000/prt0569_01_06_2000_rep.html)

Brazil. (2020a). Brazilian Health Ministry. Infecção COVID-19 e os riscos às mulheres no ciclo gravidicopuerperal. (Technical Note Publication No. 12/2020-COSMU/CGCIVI/DAPES/SAPS/MS). Federal Government of Brazil. Recovered from https://central3.to.gov.br/arquivo/505116/

Brazil. (2020b). Brazilian Health Ministry. Manual de Recomendações para a Assistência à Gestante e Puérpera frente à Pandemia de Covid-19. (Technical Note Publication No. 13/2020 - SE/GAB/SE/MS). Federal Government of Brazil. Recovered from https://saude.gov.br/images/pdf/2020/September/02/ Manual-de-Recomenda\%2D\%2D\%2D\%2Des-para-Gestante.pdf

Brazil. (2020c). Brazilian Health Ministry. Recomendações para o trabalho de parto, parto e puerpério durante a pandemia da COVID-19. (Technical Note Publication No. 9/2020-COSMU/CGCIVI/DAPES/ SAPS/MS). Federal Government of Brazil. Recovered from https:/central3.to.gov.br/arquivo/501916/

Brazil. (2020d). Brazilian Health Ministry. Recomendações para prevenção e controle de infecções pelo novo coronavirus (COVID-19) para Atenção à Gestante e Puérpera. (Technical Note Publication No. 12/2020 SESA/SSAS/GROSS/NEAPRI-REMI). Federal Government of Brazil. Recovered from https://saude.es. gov.br/Media/sesa/coronavirus/Notas\%20Técnicas/NOTA\%20TÉCNICA\%20COVID.19\%20N.\%2012. 20\%20Atenção\%20a\%C2\%A0\%20Gestante.pdf

Brazil. (2020e). Brazilian Health Ministry. Atenção à saúde do recém-nascido no contexto da infecção pelo novo coronavirus. (Technical Note Publication No. 6/2020-COCAM/CGCIVI/DAPES/SAPS/MS). Federal Government of Brazil. Recovered from https://central3.to.gov.br/arquivo/499609/

Brazilian Immunization Society. (2020). Vacinação de rotina durante a pandemia de COVID-19. (PNI Publication No. 173/2020/CGPNI/DEIDT/SVS/MS). BR National Immunization Program. Recovered from https://sbim.org.br/images/files/notas-tecnicas/nota-tecnica-sbim-vacinacao-rotina-pandemia.pdf

Brazilian Society of Pediatrics. (2020a). O aleitamento materno nos tempos de COVID-19! [Fact sheet]. Scientific Department of Breastfeeding (DCAM), Brazilian Society of Pediatrics (SBP). Recovered from https:/www.sbp.com.br/fileadmin/user_upload/22393c-Nota_de_Alerta_sobe_Aleitam_Materno_nos_ Tempos_COVID-19.pdf

Brazilian Society of Pediatrics. (2020b). Medidas para o Pediatra relacionadas com a Pandemia do COVID19. [Fact sheet]. Scientific Department of Infectious Diseases (DCI), Brazilian Society of Pediatrics (SBP). Recovered from https://www.sbp.com.br/fileadmin/user_upload/22426b-Infectologia_NAlerta_-_Medidas_p_Pediatra_relacionadas_COVID-19.pdf

Bronfenbrenner, U. (1979). The ecology of human development: Experiments by nature and design. Harvard University Press.

Bronfenbrenner, U. (2005). Making human beings human: Bioecological perspectives on human development. Sage Publications Ltd..

Burns, E., \& Schmied, V. (2017). "The right help at the right time": Positive constructions of peer and professional support for breastfeeding. Women and birth: journal of the Australian College of Midwives, 30(5), 389-397. https://doi.org/10.1016/j.wombi.2017.03.002.

Carver, C. S., \& Connor-Smith, J. (2010). Personality and coping. Annual Review of Psychology, 61(1), 679704. https://doi.org/10.1146/annurev.psych.093008.100352.

Carver, C. S., \& Scheier, M. F. (1994). Situational coping and coping dispositions in a stressful transaction. Journal of personality and social psychology, 66(1), 184-195. https://doi.org/10.1037//0022-3514.66.1. 184. 
Carver, C. S., Scheier, M. F., \& Weintraub, J. K. (1989). Assessing coping strategies: A theoretically based approach. Journal of Personality and Social Psychology, 56(2), 267-283. https://doi.org/10.1037/00223514.56.2.267.

Carver, C. S., Scheier, M. F., \& Segerstrom, S. C. (2010). Optimism. Clinical Psychol, 30(7), 879-889. https://doi.org/10.1016/j.cpr.2010.01.006.

Cassepp-Borges, V., Balbinotti, M., \& Teodoro, M. (2010). Tradução e validação de conteúdo: Uma proposta para a adaptação de instrumentos. Instrumentação psicológica: Fundamentos e práticas, 506-520.

Centers for Disease Control and Prevention. (2020a). Coronavirus disease (COVID-19) and breastfeeding. Recovered from https://www.cdc.gov/breastfeeding/breastfeeding-special-circumstances/maternal-orinfant-illnesses/covid-19-and-breastfeeding.html

Centers for Disease Control and Prevention. (2020b). Evaluation and management considerations for neonates at risk for COVID-19. Recovered from https:/www.cdc.gov/coronavirus/2019-ncov/hcp/ caring-for-newborns.html

Chen, N., Zhou, M., Dong, X., Qu, J., Gong, F., Han, Y., Qiu, Y., Wang, J., Liu, Y., Wei, Y., Xia, J., Yu, T., Zhang, X., \& Zhang, L. (2020). Epidemiological and clinical characteristics of 99 cases of 2019 novel coronavirus pneumonia in Wuhan, China: A descriptive study. The Lancet, 395, 507-513. https://doi.org/ 10.1016/S0140-6736(20)30211-7.

Ciampo, L. A. D., \& Ciampo, I. R. L. D. (2018). Breastfeeding and the benefits of lactation for women's health. Revista Brasileira de Ginecologia e Obstetricia / RBGO Gynecology and Obstetrics, 40(6), 354 359. https://doi.org/10.1055/s-0038-1657766.

Clout, D., \& Brown, R. (2015). Sociodemographic, pregnancy, obstetric, and postnatal predictors of postpartum stress, anxiety and depression in new mothers. Journal of Affective Disorders, 188, 60-67. https://doi. org/10.1016/j.jad.2015.08.054.

Corrigan, C. P., Kwasky, A. N., \& Groh, C. J. (2015). Social support, postpartum depression, and professional assistance: A survey of mothers in the Midwestern United States. The Journal of perinatal education, 24(1), 48-60. https://doi.org/10.1891/1058-1243.24.1.48.

Echer, I. C. (2005). The development of handbooks of health care guidelines. Revista Latino-Americana de Enfermagem, 13(5), 754-757. https://doi.org/10.1590/S0104-11692005000500022.

Feltner, C., Weber, R. P., Stuebe, A., Grodensky, C. A., Colin, O. C., \& Viswanatha M. (2018). Breastfeeding programs and policies, breastfeeding uptake, and maternal health outcomes in developed countries. Comparative Effectiveness Review, 210. doi: https://www.ncbi.nlm.nih.gov/sites/books/NBK525106/

Fernandes, D. V., Canavarro, M. C., \& Moreira, H. (2020). The mediating role of parenting stress in the relationship between anxious and depressive symptomatology, mothers' perception of infant temperament, and mindful parenting during the postpartum period. Mindfulness., 12, 275-290. https://doi.org/10. 1007/s12671-020-01327-4.

Fiocruz Brazilian Human Milk Bank Network (rBLH-BR). (2020). Covid-19: rBLH-BR divulga recomendações sobre amamentação [Fact sheet]. Recovered from: Oswaldo Cruz Brazilian Foundation (Fiocruz) https://portal.fiocruz.br/noticia/covid-19-rblh-divulga-recomendacoes-sobreamamentacao.

Fiorillo, A., \& Gorwood, P. (2020). The consequences of the COVID-19 pandemic on mental health and implications for clinical practice. European Psychiatry, 63(1) Article e32, 1-2. https://doi.org/10.1192/j. eurpsy.2020.35.

Fonseca, L. M. M., Scochi, C. G. S., Rocha, S. M. M., \& Leite, A. M. (2004). Cartilha educativa para orientação materna sobre os cuidados com o bebê prematuro. Rev Latino-am Enfermagem, 12(1), 65-75. https://doi.org/10.1590/S0104-11692004000100010.

Gaillard, A., Le Strat, Y., Mandelbrot, L., Keïta, H., \& Dubertret, C. (2014). Predictors of postpartum depression: Prospective study of 264 women followed during pregnancy and postpartum. Psychiatry Research, 215(2), 341-346. https://doi.org/10.1016/j.psychres.2013.10.003.

Grossman, P., Niemann, L., Schimidt, S., \& Walach, H. (2004). Mindfulness-based stress reduction and health benefits: A meta-analysis. Journal of Psychosomatic Research, 57(1), 35-43. https://doi.org/10.1016/ S0022-3999(03)00573-7.

Hernández-Nieto, R. A. (2002). Contributions to statistical analysis. Mérida: Universidad de Los Andes.

Ho, C. S., Chee, C. Y., \& Ho, R. C. (2020). Mental health strategies to combat the psychological impact of COVID-19 beyond paranoia and panic. Annals of the Academy of Medicine, Singapore, 49(3), 155-160 doi: https://pubmed.ncbi.nlm.nih.gov/32200399/.

Hoffman, C., Dunn, D. M., \& Njoroge, W. (2017). Impact of postpartum mental illness upon infant development. Current psychiatry reports, 19(12), 100. https://doi.org/10.1007/s11920-017-0857-8. 
Holt-Lunstad, J., Smith, T. B., Baker, M., Harris, T., \& Stephenson, D. (2015). Loneliness and social isolation as risk factors for mortality. Perspectives on Psychological Science, 10(2), 227-237. https://doi.org/10. $1177 / 1745691614568352$.

Huang, Y., \& Zhao, N. (2020). Generalized anxiety disorder, depressive symptoms and sleep quality during COVID-19 outbreak in China: A web-based cross-sectional survey. Psychiatry Research, 288. https://doi. org/10.1016/j.psychres.2020.112954.

Lazarus, R. S., \& Folkman, S. (1984). Stress, appraisal and coping. Springer Publishing Company.

Leahy-Warren, P. (2005). First-time mothers: Social support and confidence in infant care. J. Adv. Nurs, 50(5), 479-488. https://doi.org/10.1111/j.1365-2648.2005.03425.x.

Linhares, M. B. M., \& Enumo, S. R. F. (2020). Reflections based on psychology about the effects of COVID19 pandemic on child development. Estudos de Psicologia (Campinas), 37, Article e200089. https://doi. org/10.1590/1982-0275202037e200089.

Neff, K. D. (2009). Self-Compassion. In M. R. Leary \& R. H. Hoyle (Eds.), Handbook of individual differences in social behavior (pp. 561-573). Guilford Press.

Peterson, C., \& Seligman, M. E. P. (2004). Character strengths and virtues: A handbook and classification. In American Psychological Association. Oxford University Press.

Poles, M. M., Carvalheira, A. P. P., Carvalhaes, M. A. B. L., \& Parada, C. M. G. L. (2018). Maternal depressive symptoms during immediate postpartum: Associated factors. Acta Paulista de Enfermagem, 31(4), 351-358. https://doi.org/10.1590/1982-0194201800050.

Qobadi, M., Collier, C., \& Zhang, L. (2016). The effect of stressful life events on postpartum depression: Findings from the 2009-2011 Mississippi pregnancy risk assessment monitoring system. Maternal and child health journal, 20(Suppl 1), 164-172. https://doi.org/10.1007/s10995-016-2028-7.

Ramírez-Ortiz, J., Castro-Quintero, D., Lerma-Córdoba, C., Yela-Ceballos, F., \& Escobar-Córdoba, F. (2020). Consecuencias de la pandemia COVID-19 en la Salud Mental asociadas al aislamiento social. SciELO Preprints, 1-21. https://doi.org/10.1590/SCIELOPREPRINTS.303.

Rashid, T., \& Seligman, M. P. (2018). Positive psychotherapy: Clinical manual. Oxford University Press.

Redzuan, S. A. M., Suntharalingam, P., Palaniyappan, T., Ganasan, V., Bakar, P. N. M. A., Kaur, P., Marmuji, L. Z., Ambigapathy, S., Paranthaman, V., \& Chew, B. H. (2020). Prevalence and risk factors of postpartum depression, general depressive symptoms, anxiety and stress (PODSAS) among mothers during their 4-week postnatal follow-up in five public health clinics in Perak: A study protocol for a crosssectional study. BMJ open, 10(6), Article e034458. https://doi.org/10.1136/bmjopen-2019-034458.

Rodrigues, O. M. P. R., \& Schiavo, R. A. (2011). Stress na gestação e no puerpério: uma correlação com a depressão pós-parto. Revista Brasileira de Ginecologia e Obstetrícia, 33(9), 252-257. https://doi.org/10. 1590/S0100-72032011000900006.

Royal College of Obstetricians and Gynaecologists. (2020). Coronavirus (COVID-19) infection in pregnancy. Information for healthcare professionals. (Version 1: Published Monday 9 March, 2020.) Recovered from https:/www.rcog.org.uk/globalassets/documents/guidelines/coronavirus-covid19-virus-infection-inpregnancy-2020-03-09.pdf

Royal College of Psychiatrists. (2011). The Mental Health of Students in Higher Education (College Report CR166). Royal College of Psychiatrists. Recovered from .https://www.rcpsych.ac.uk/docs/default-source/ improving-care/better-mh-policy/college-reports/college-report-cr166.pdf?sfvrsn=d5fa2c24_2

Schmidt, B., Crepaldi, M. A., Bolze, S. D. A., Neiva-Silva, L., \& Demenech, L. M. (2020). Mental health and psychological interventions during the new coronavirus pandemic (COVID-19). Estudos de Psicologia (Campinas), 37, Article e200063. https://doi.org/10.1590/1982-0275202037e200063.

Seligman, M. (2011). Flourish: A visionary new understanding of happiness and well-being. New York: Atria Paperback.

Seligman, M., \& Csikszentmihalyi, M. (2000). Positive psychology: An introduction. American Psychologist, $55,5-14$.

Singer, T., \& Klimecki, O. M. (2014). Empathy and compassion. Current Biology, 24(18), 875-878. https:// doi.org/10.1016/j.cub.2014.06.054.

Slomian, J., Honvo, G., Patrick, E., Reginster, J., \& Olivier, B. (2019). Consequences of maternal postpartum depression: A systematic review of maternal and infant outcomes. Women's Health, 15(1), 1-55. https:// doi.org/10.1177/2F1745506519844044.

Spinola, O., Liotti, M., Speranza, A. M., \& Tambelli, R. (2020). Effects of COVID-19 epidemic lockdown on postpartum depressive symptoms in a sample of Italian mothers. Frontiers in psychiatry, 11, Article e589916. https://doi.org/10.3389/fpsyt.2020.589916.

Wang, C., Pan, R., Wan, X., Tan, Y., Xu, L., Ho, C. S., \& Ho, R. C. (2020a). Immediate psychological responses and associated factors during the initial stage of the 2019 coronavirus disease (COVID-19) 
epidemic among the general population in China. International journal of environmental research and public health, 17(5), 1729. https://doi.org/10.3390/ijerph17051729.

Wang, J., Wang, J., \& Yang, G. (2020). The psychological impact of COVID-19 on Chinese who individuals. Brief Communication, 61(5), 438-440. https://doi.org/10.3349/ymj.2020.61.5.438.

Wong, B. (2011). The design process. Nat Methods, 987(8), 987. https://doi.org/10.1038/nmeth.1783.

World Health Organization. (2009). United Nations Population Fund. Mental health aspects of women's reproductive health. A global review of the literature. Geneva: WHO Press. Recovered from https://apps. who.int/iris/bitstream/handle/10665/43846/9789241563567_eng.pdf?sequence=1\&isAllowed=y

World Health Organization. (2020) Infection prevention and control during health care when novel coronavirus (NCOV) infection is suspected. OMS. Recovered from https://www.who.int/publications/i/item/ infection-prevention-and-control-during-health-care-when-novel-coronavirus-(ncov)-infection-issuspected-20200125

Wouk, K., Tucker, C., Pence, B. W., Meltzer-Brody, S., Zvara, B., Grewen, K., \& Stuebe, A. M. (2019). Positive emotions during infant feeding and breastfeeding outcomes. Journal of Human Lactation, 36(1), 157-167. https://doi.org/10.1177/2F0890334419845646.

Zandifar, A., \& Badrfam, R. (2020). Iranian mental health during the COVID-19 epidemic. Asian Journal of Psychiatry, 51, Article e101990. https://doi.org/10.1016/j.ajp.2020.101990.

Zanon, C., Dellazzana-Zanon, L. L., Wechsler, S. M., Fabretti, R. R., \& da Rocha, K. N. (2020). COVID-19: Implications and applications of positive psychology in times of pandemic. Estudos de Psicologia (Campinas), 37, Article e200072. https://doi.org/10.1590/1982-0275202037e200072. 